Document downloaded from:

http://hdl.handle.net/10251/65523

This paper must be cited as:

Gallardo Bermell, S.; Querol Vives, A.; Ortiz Moragón, J.; Ródenas Diago, J.; Verdú Martín, GJ.; Villanueva López, JF. (2015). Uncertainty analysis in environmental radioactivity measurements using the Monte Carlo code MCNP5. Radiation Physics and Chemistry. 116:214-218. doi:10.1016/j.radphyschem.2015.05.023.

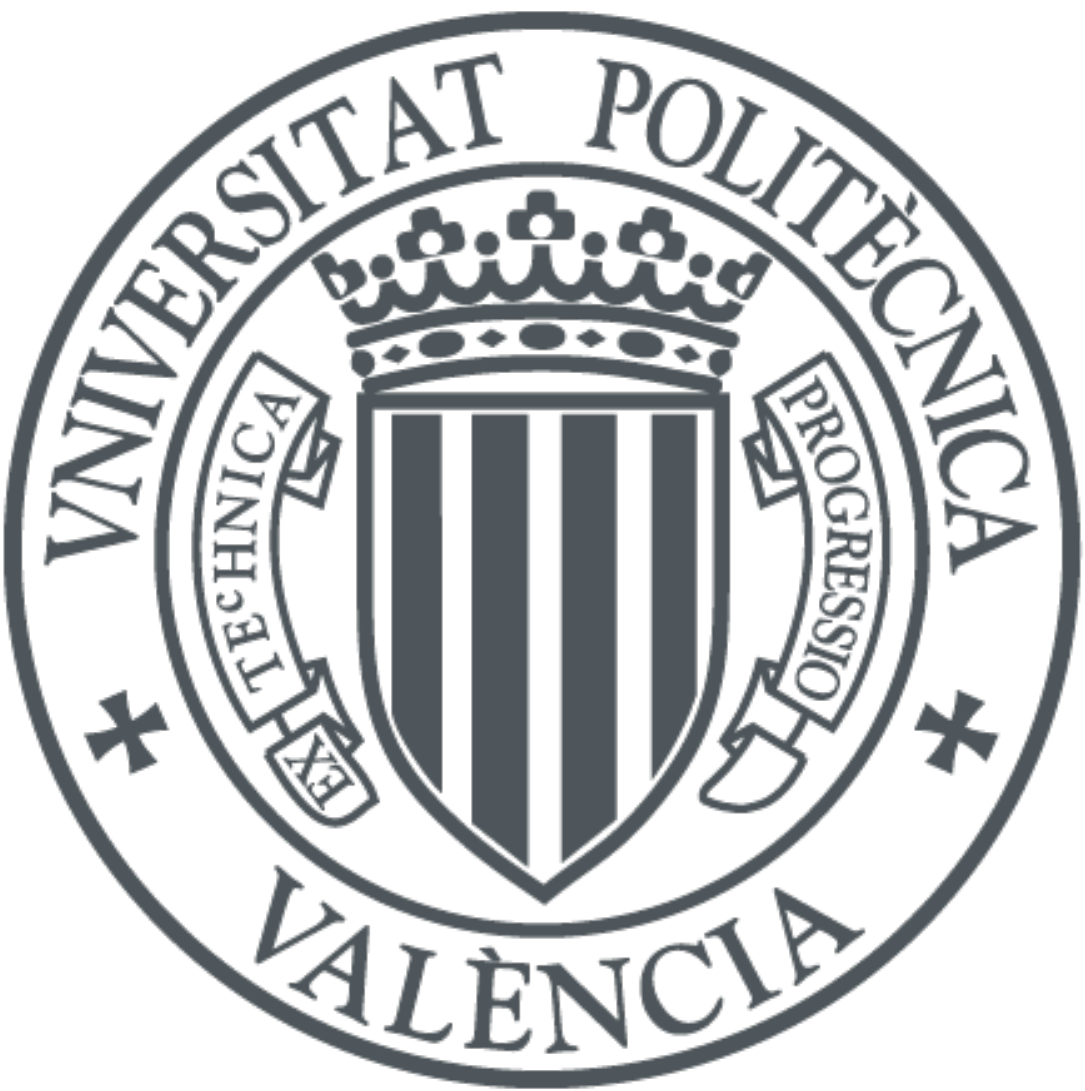

The final publication is available at

http://dx.doi.org/10.1016/j.radphyschem.2015.05.023

Copyright Elsevier

Additional Information 


\title{
Uncertainty analysis in environmental radioactivity measurements using the Monte Carlo code MCNP5
}

\author{
S. Gallardo ${ }^{1}$, A. Querol, J. Ortiz ${ }^{\mathrm{a}}$, J. Ródenas, G. Verdú and J. F. Villanueva ${ }^{\mathrm{b}}$ \\ Instituto de Seguridad Industrial, Radiofísica y Medioambiental, Universitat Politècnica de \\ València, Spain. \\ ${ }^{a}$ Laboratorio de Radiactividad Ambiental, Universitat Politècnica de València, Spain. \\ ${ }^{\mathrm{b}}$ Departamento de Ingeniería Química y Nuclear, Universitat Politècnica de València, Spain.
}

Keywords: HPGe detector, Monte Carlo, efficiency, uncertainties.

\begin{abstract}
High Purity Germanium (HPGe) detectors are widely used for environmental radioactivity measurements due to their excellent energy resolution. Monte Carlo (MC) codes are a useful tool to complement experimental measurements in calibration procedures at the laboratory. However, the efficiency curve of the detector can vary due to uncertainties associated with measurements. These uncertainties can be classified into some categories: geometrical parameters of the measurement (distance source-detector, volume of the source), properties of the radiation source (radionuclide activity, branching ratio), and detector characteristics (Ge dead layer, active volume, end cap thickness). The Monte Carlo simulation can be also affected by other kind of uncertainties mainly related to cross sections and to the calculation itself. Normally, all these uncertainties are not well known and it is required a deep analysis to determine their effect on the detector efficiency. In this work, the Noether-Wilks formula is used to carry out the uncertainty analysis. A Probability Density Function (PDF) is assigned to each variable involved in the sampling process. The size of the sampling is determined from the characteristics of the tolerance intervals by applying the Noether-Wilks formula. Results of the analysis transform the efficiency curve into a region of possible values into the tolerance intervals. Results show a good agreement between experimental measurements and simulations for two different matrices (water and sand).
\end{abstract}

\section{INTRODUCTION}

A gamma spectrometer including an HPGe detector is commonly used for environmental radioactivity measurements. One of the main concerns in gamma spectrometry is the proper characterization of the efficiency curve in the energy range of interest for environmental radioactivity measurements. In this frame, Monte Carlo (MC) methods are powerful tools not only for the efficiency determination (Blank et al., 2015; Eren et al., 2015; Conti et al., 2013; Nikolic et al., 2014; Salvat et al., 2011; Agostinelli et al., 2003), but also for dead layer estimation (Chham et al., 2015; Andreotti et al., 2014; Ródenas et al., 2007), uncertainty analysis or true coincidence summing analysis (Vidmar et al., 2014; Lépy et al., 2012).

Some of the data required for the detector simulation are found in the certificate provided by the manufacturer, where the main characteristics are described. In general, manufacturers do not offer detailed information about Ge dead layer (thickness and variation along with time), which strongly affects the measurements. An over or underestimation of the dead layer thickness produces strong effects in the value of the efficiency (Ngo, 2010).

\footnotetext{
${ }^{1}$ Corresponding author. Phone number: +34963879631 . Fax: +34 963877634. email:

sergalbe@iqn.upv.es
} 
In environmental radioactivity, different geometries and matrices are used depending on the measurements, sources, etc. Some of the most used geometries are Petri dish and Marinelli beaker. This work is focused on obtaining the calibration curve for a $100 \mathrm{~cm}^{3}$ Petri dish filled with two different materials: water and sand. For this aim, the Monte Carlo code MCNP5 (X-5 Monte Carlo Team, 2003) has been used. However, efficiency curve is affected by several factors, which are not taken into account in common simulations.

Geometrical uncertainties are mainly due to the Ge dead layer thickness of the crystal and to the experiment itself. In general and in order to consider the effect of these uncertainties, the guide JCGM 101:2008 is used. This guide studies the propagation of distributions using a Monte Carlo method. The approach followed in this paper is based on non-parametric methods. The uncertainty analysis has been performed using the Noether-Wilks formula (Wilks, 1962; Galeser el al., 1994). This method can be used independently of the number and distribution of input uncertainties, and where the distribution of the variable of interest (output variable) cannot be known.

\section{MATERIALS AND METHODS}

\subsection{Experimental Equipment}

An HPGe coaxial detector system has been used for experimental measurements at the Laboratorio de Radiactividad Ambiental (LRA) of the Universitat Politècnica de València (UPV). The detector model is ORTEC GMX 40P4, with a closed-end coaxial geometry. The main specifications of the detector are the following: $40 \%$ relative efficiency at $1.33 \mathrm{MeV} \mathrm{Co}-60$; FWHM resolution of $2.0 \mathrm{keV}$; peak shape FWTM/FWHM 2.0 at $1.33 \mathrm{MeV}$ Co-60; and the peakto-Compton ratio 59 for Co-60. The crystal diameter is $60 \mathrm{~mm}$ and the length is $71.1 \mathrm{~mm}$. The core hole diameter is $9 \mathrm{~mm}$, and the core hole length is $63.1 \mathrm{~mm}$. The end cap to crystal distance is $4 \mathrm{~mm}$. The cup length is $105 \mathrm{~mm}$. The window material is beryllium with $0.5 \mathrm{~mm}$ thickness. The crystal has also a layer $0.03 \mathrm{~mm}$ of Mylar in front of the cryostat window. The effective thickness of the dead layer is not well known due to the existence of a transition zone between the inactive layer and the active germanium in the crystal whose thickness is very difficult to be accurately estimated. The manufacturer provides a value of $700 \mu \mathrm{m} \mathrm{Ge} / \mathrm{Li}$ dead layer in the crystal inner hole and $0.3 \mu \mathrm{m} \mathrm{Ge} / \mathrm{B}$ dead layer in the top and lateral crystal sides. The Petri box is made of polyethylene and radionuclides are added to a matrix (water or sand). The source used for measurements is a calibration gamma standard solution, covering the energy range between 59 and $1800 \mathrm{keV}$. The radionuclides contained in the source solution are listed in Table 1 together with their main peak energy, branching ratio and certified activity.

Table 1. Gamma standard features.

\begin{tabular}{|c|c|c|c|c|c|c|}
\hline Nuclide & $\begin{array}{c}\text { Energy } \\
(\mathrm{keV})\end{array}$ & $\begin{array}{c}\text { Branching } \\
\text { ratio }\end{array}$ & $\begin{array}{c}\text { Activity }(\mathrm{Bq}) \\
\text { Water sample }\end{array}$ & $\begin{array}{c}\text { Gamma/s } \\
\text { in Water sample }\end{array}$ & $\begin{array}{c}\text { Activity (Bq) } \\
\text { Sand sample }\end{array}$ & $\begin{array}{c}\text { Gamma/s } \\
\text { in Sand sample }\end{array}$ \\
\hline${ }^{241} \mathrm{Am}$ & 59.54 & 35.90 & 71.52 & 25.69 & 99.73 & 35.82 \\
\hline${ }^{109} \mathrm{Cd}$ & 87.90 & 3.61 & 363.23 & 13.17 & 506.51 & 18.37 \\
\hline${ }^{109} \mathrm{Co}$ & 122.06 & 85.59 & 13.39 & 11.45 & 18.67 & 15.96 \\
\hline${ }^{139} \mathrm{Ce}$ & 165.85 & 79.95 & 14.44 & 11.54 & 20.13 & 16.08 \\
\hline${ }^{51} \mathrm{Cr}$ & 320.15 & 9.83 & 268.44 & 26.50 & 374.32 & 36.95 \\
\hline${ }^{113} \mathrm{Sn}$ & 391.74 & 64.16 & 54.33 & 35.30 & 75.76 & 49.22 \\
\hline${ }^{85} \mathrm{Sr}$ & 513.95 & 98.30 & 47.99 & 47.27 & 66.91 & 65.91 \\
\hline${ }^{137} \mathrm{Cs}$ & 661.59 & 85.21 & 68.54 & 58.25 & 95.58 & 81.23 \\
\hline${ }^{54} \mathrm{Mn}$ & 834.90 & 99.97 & 64.41 & 64.40 & 89.82 & 89.79 \\
\hline${ }^{88} \mathrm{Y}$ & 898.24 & 95.00 & 98.36 & 92.36 & 137.16 & 128.79 \\
\hline${ }^{65} \mathrm{Zn}$ & 1115.00 & 50.74 & 137.36 & 68.98 & 191.55 & 96.19 \\
\hline${ }^{60} \mathrm{Co}$ & 1173.24 & 99.90 & 72.68 & 72.57 & 101.35 & 101.20 \\
\hline
\end{tabular}




\begin{tabular}{|c|c|c|c|c|c|c|}
\hline${ }^{60} \mathrm{Co}$ & 1332.53 & 99.98 & 72.67 & 72.66 & 101.34 & 101.33 \\
\hline${ }^{88} \mathrm{Y}$ & 1835.98 & 99.35 & 98.27 & 97.6 & 137.03 & 136.10 \\
\hline
\end{tabular}

By direct measurement of calibration sources, experimental efficiencies in the energy range between 59 and $1800 \mathrm{keV}$ were calculated. The experimental efficiency at energy E $\gamma$ for a given measuring condition is:

$$
\mathrm{Eff}_{\mathrm{Ei}}=\frac{\mathrm{N}_{\mathrm{Ei}}}{\mathrm{Amtf}}
$$

where $\mathrm{N}_{\mathrm{Ei}}$ is the net area under the full-energy peak corresponding to $E_{\mathrm{i}}$ energy photons emitted by a radionuclide with a known specific activity, $\mathrm{A}$, $\mathrm{f}$ is the branching ratio, $\mathrm{m}$ is the sample mass and $t$ is the counting time (Debertin et al., 1988).

\subsection{MCNP Model}

The MCNP5 code has been used for simulating the whole detection device of LRA (Ródenas et al., 2007). MCNP5 is an advanced Monte Carlo code, which contains the necessary cross-section data for neutron, photon, and electron transport calculations. An MCNP5 model has been developed for the system defined by the HPGe detector and the Petri dish. The Petri dish, filled with water or sand containing the calibration gamma solution, is placed directly on the top of the detector providing a relatively high-efficiency geometry. Figure 1 shows the geometry and materials of the different layers included in the system detector-source.

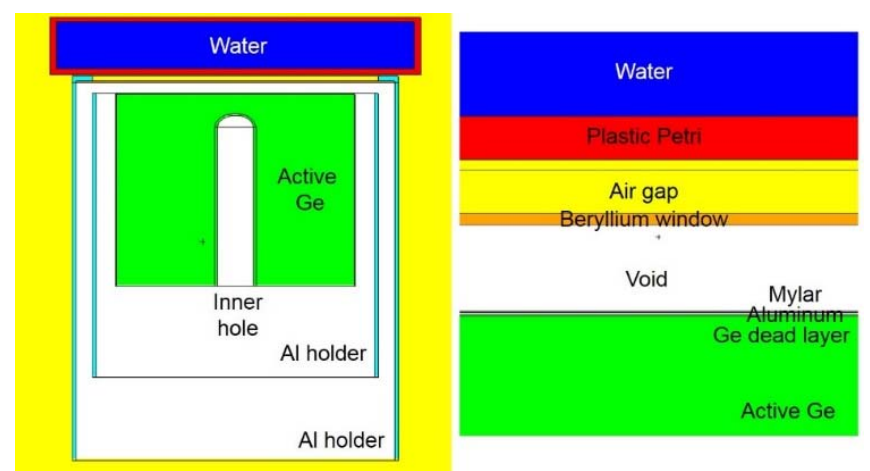

Figure 1. Geometrical model.

Photon and electron transport are considered in the MCNP5 model. The F8 tally (Pulse Height Distribution) has been used for photons and electrons. 8192 bins corresponding to the number of channels of the actual detector device have been used. Detailed physics has been taken into account (photoelectric effect with fluorescence production and incoherent scattering with form factors) in the energy range between 1 and $2000 \mathrm{keV}$. Electron generation and tracks have been considered in the simulation (MODE P E in MCNP). The use of the GEB (Gaussian Energy Broadening) card option provides a spectrum that can be compared with the experimental one in terms of resolution (FWHM). The GEB parameters specify the FWHM of the observed energy broadening in a physical radiation detector, according to Equation 2:

$$
\operatorname{FWHM}(\mathrm{MeV})=\mathrm{a}+\mathrm{b} \sqrt{\mathrm{E}+\mathrm{c} E^{2}}
$$

where $\mathrm{E}$ is the energy of the particle $(\mathrm{MeV})$. In the case analyzed, $\mathrm{a}=5.063 \mathrm{E}-04 \mathrm{MeV}, \mathrm{b}=8.922 \mathrm{E}-$ $04 \mathrm{MeV}^{1 / 2}$ and $\mathrm{c}=8.096 \mathrm{E}-01\left(\mathrm{MeV}^{-1}\right)$.

\subsection{Uncertainty analysis}

In an MC simulation, uncertainties can be attributed to different causes: 1) Statistical: due to the stochastic nature of the $\mathrm{MC}$ method and the finite number of simulated events. Normally statistical uncertainties are given by $\mathrm{MC}$ codes along with results of calculations. 2) Input: due to the input 
parameters such as density, geometrical dimensions and material composition. 3) Physics: due to any systematic difference between the way the simulation models radiation interactions with matter and the way these interactions really occur (JCGM 101:2008). To perform an uncertainty analysis of some variables, it is necessary to assign a PDF to each variable before the sampling. This initial phase of the analysis is the most subjective step of the entire process. One of the most frequently used PDFs is the uniform distribution, which assigns equal probability to any value in the range of variation of the variable. Normal and lognormal distributions are commonly used to describe experimental measurements and other natural variations.

The size of the sampling is determined from the characteristics of the tolerance intervals by applying the Noether-Wilks formula (Wilks, 1962, Galeser et al., 1994). Thus, the number of required calculations does not depend on the number of input parameters neither on any assumption about the probability distribution of results (Crow, 1960). Wilks' method is based on the idea of determining the minimum number of simulations of the code in order to infer a certain coverage of a population $\mathrm{p}$, with a certain confidence, $\gamma$. The probability distribution of the output $\mathrm{f}(\mathrm{x})$ is an unknown function. Tolerance limits are obtained using the Wilks method as:

$$
P\left(\int_{L}^{U} f(x) d x>\gamma\right)=\beta
$$

where $\mathrm{L}$ and $\mathrm{U}$ are the lower and upper tolerance limits.

Next, a set of result parameter values picked from the unknown distribution $f(x)$ are arranged in ascending order. Equation (3) can be written as

$$
\beta \leq 1-\sum_{j-s-r}^{n}\left(\begin{array}{l}
n \\
j
\end{array}\right) y^{j}(1-y)^{N-j}
$$

where the minimum value is marked with index $r$ and the maximum value with index $s$.

In the case of the two sided tolerance interval the lower tolerance limit is the lowest value obtained and the upper tolerance limit is the highest value obtained in the random sample. Substituting $\mathrm{s}=\mathrm{n}$ and $r=1$ in Equation (4) the following expression is obtained (Guba et al., 2003):

$$
\beta \leq 1-\gamma^{n}-(n-1)(1-\gamma) \gamma^{n-1}
$$

To estimate the tolerance interval with a $95 \%$ of confidence level the minimum number of MC simulations required is 93 . After the PDFs and ranges of variation were assigned to the input variables and code models, the value of these random variables was sampled. The precision of the results does not depend on the number of input parameters, but on the sample size and randomness of the sampling procedure among other factors (Wilks, 1962). Table 2 lists the variables considered in the Wilks analysis. All these variables specify geometrical parameters of the detector, the source (Petri dish) and the distance between the source and the detector.

Table 2. Parameters considered in the uncertainty analysis.

\begin{tabular}{|l|c|c|}
\hline \multicolumn{1}{|c|}{ Item } & $\begin{array}{c}\text { Nominal } \\
\text { value }(\mathrm{cm})\end{array}$ & $\begin{array}{c}\text { Standard } \\
\text { deviation }\end{array}$ \\
\hline Top Dead Layer & 0.007500 & \pm 0.000375 \\
\hline Void 1 & 0.0100 & \pm 0.0005 \\
\hline Aluminum & 0.00300 & \pm 0.00015 \\
\hline Mylar & 0.00300 & \pm 0.00015 \\
\hline Void 2 & 0.60 & \pm 0.02 \\
\hline Beryllium & 0.0500 & \pm 0.0025 \\
\hline Edge & 0.15 & \pm 0.01 \\
\hline
\end{tabular}




\begin{tabular}{|l|c|c|}
\hline Air & 0.0500 & \pm 0.0025 \\
\hline Plastic bottom Petri dish & 0.20 & \pm 0.01 \\
\hline Matrix Petri dish & 1.75000 & \pm 0.04375 \\
\hline Plastic top Petri dish & 0.20 & \pm 0.01 \\
\hline Internal lateral Dead Layer & 0.07 & \pm 0.0035 \\
\hline External lateral Dead Layer & 0.007500 & \pm 0.000375 \\
\hline Void internal & 0.500 & \pm 0.025 \\
\hline Aluminum internal lateral & 0.080 & \pm 0.004 \\
\hline Void external lateral & 0.420 & \pm 0.021 \\
\hline Aluminum external lateral & 0.100 & \pm 0.005 \\
\hline
\end{tabular}

Regarding to the detector, the parameters taken into account are: aluminum, mylar and beryllium layer thickness, dead layer (top, lateral and inner hole inactive germanium thickness) and void volume. With respect to the Petri, the thickness of the plastic (bottom, lateral and top) and the total matrix volume (water or sand) have been considered. It has been assumed that parameters listed in Table 2 have a normal distribution defined by a mean value and a standard deviation.

\section{RESULTS AND DISCUSSION}

Efficiency curves simulated using the MCNP5 code are compared with experimental ones. All of the parameters given by the manufacturer including dead layer thickness have been considered in the models. Efficiencies are calculated in the energy range defined by the standard solution. A Petri dish of $100 \mathrm{~cm}^{3}$ has been used in both experimental measurements and simulations. Water and sand matrices have been analyzed. Among the analyzed radionuclides (Table 1), Y-88 and Co-60 are gamma emitters that present true coincidence phenomena due to a cascade photon emission. A quasi-point method has been used to correct coincidences (Montgomery et al., 1995). The coincidence summing correction factor is the multiplicative factor to convert a measured gamma-ray efficiency with summing effects to an efficiency with no summing effects. The coincidence summing correction factor can be calculated from the equation (4).

$$
C_{c}=\frac{1}{1-\sum_{i=1}^{i=j} f_{i} \varepsilon_{i}(i)}
$$

where $f_{\mathrm{i}}=$ the fraction of coincidence photons of energy $i$ in coincidence with the gamma ray of interest, and $\varepsilon_{i}(i)$ is the total efficiency of the coincidence photon of energy i.

To estimate the coincidence summing correction factor for both ${ }^{60} \mathrm{Co}(1173$ and $1332 \mathrm{keV})$ and ${ }^{88} \mathrm{Y}(898$ and $1836 \mathrm{keV}$ ), four monoenergetic beams have been simulated and the total efficiency have been determined for each of them. From these results and applying Eq. 4, then correction factors are obtained: for ${ }^{60} \mathrm{Co}$ (1.09 and 1.09) and for ${ }^{88} \mathrm{Y}$ (1.1 and 1.09). Once correction factors have been estimated, simulated efficiencies of ${ }^{60} \mathrm{Co}$ and ${ }^{88} \mathrm{Y}$ have been corrected.

Net area of the full energy peaks of interest $\left({ }^{241} \mathrm{Am},{ }^{109} \mathrm{Cd},{ }^{57} \mathrm{Co},{ }^{51} \mathrm{Cr},{ }^{113} \mathrm{Sn},{ }^{85} \mathrm{Sr},{ }^{137} \mathrm{Cs},{ }^{54} \mathrm{Mn},{ }^{88} \mathrm{Y}\right.$ (898), ${ }^{60} \mathrm{Co}(1117),{ }^{60} \mathrm{Co}(1332)$ and $\left.{ }^{88} \mathrm{Y}(1898)\right)$ has been determined. Experimental efficiencies for water and sand are listed in Table 3. Using nominal values for variables listed in Table2, simulated efficiencies are obtained with MCNP5 (see Table 3). As it can be seen, relative errors between experimental and simulated efficiencies are less than 5\% in almost all cases. Relative error of MCNP5 calculations are lower than $1 \%$ in any case.

The efficiency obtained for ${ }^{241} \mathrm{Am},{ }^{109} \mathrm{Cd}$ and ${ }^{57} \mathrm{Co}$ is lower $(21 \%, 15 \%$ and $10 \%$, respectively) in sand matrix than in water. This effect is gradually reduced when energy increases, and finally, differences are lower than $3 \%$ for energies corresponding to ${ }^{88} \mathrm{Y}$ and ${ }^{60} \mathrm{Co}$.

Discrepancies between experimental and simulated curves can be partially attributed to uncertainties of the actual crystal active volume. In fact, the active volume of HPGe is not well 
known and normally manufacturers do not give exhaustive information about that. Furthermore, dead layer thickness increases in aged detectors. Uncertainties related to geometrical aspects of the experiment (distance source-detector, volume of the Petri) can also affect the efficiency.

An uncertainty analysis using the Noether-Wilks formula has been performed to determine the global effect of the main variables affecting the geometry of the model. Furthermore, a sensitivity analysis is presented to highlight the relative importance of each variable in the efficiency curve.

Table 3. Experimental and simulated results. Petri $100 \mathrm{~cm}^{3}$.

\begin{tabular}{|c|c|c|c|c|c|c|c|c|c|}
\hline \multicolumn{2}{|c|}{} & \multicolumn{6}{|c|}{ Water } & \multicolumn{5}{c|}{ Sand } \\
\hline Nuclide & $\begin{array}{l}\text { Energy } \\
(\mathrm{keV})\end{array}$ & $\begin{array}{l}\text { Experimental } \\
\text { efficiency }\end{array}$ & $\begin{array}{l}\text { SD } \\
2-\sigma \\
(\%)\end{array}$ & MCNP & MCNP/exp & $\begin{array}{l}\text { Experimental } \\
\text { efficiency }\end{array}$ & $\begin{array}{l}\text { SD } \\
2-\sigma \\
(\%)\end{array}$ & MCNP $\left.{ }^{*}\right)$ & MCNP/exp \\
\hline${ }^{241} \mathrm{Am}$ & 59.54 & 0.09041 & 1.0 & 0.08539 & 0.94 & 0.070714 & 0.9 & 0.07186 & 1.02 \\
\hline${ }^{109} \mathrm{Cd}$ & 88.03 & 0.09580 & 2.3 & 0.09232 & 0.96 & 0.082874 & 1.4 & 0.08338 & 1.01 \\
\hline${ }^{109} \mathrm{Co}$ & 122.1 & 0.08968 & 1.3 & 0.08649 & 0.96 & 0.080414 & 0.1 & 0.07984 & 0.99 \\
\hline${ }^{139} \mathrm{Ce}$ & 165.9 & 0.07580 & 1.8 & 0.07654 & 1.01 & 0.0692 & 0.1 & 0.07108 & 1.03 \\
\hline${ }^{51} \mathrm{Cr}$ & 320.0 & 0.04709 & 1.7 & 0.04610 & 0.98 & 0.043826 & 1.0 & 0.04347 & 0.99 \\
\hline${ }^{113} \mathrm{Sn}$ & 391.7 & 0.03970 & 1.4 & 0.03955 & 1.00 & 0.036565 & 0.5 & 0.03760 & 1.03 \\
\hline${ }^{85} \mathrm{Sr}$ & 514.0 & 0.03077 & 1.6 & 0.03110 & 1.01 & 0.029823 & 0.8 & 0.02968 & 1.00 \\
\hline${ }^{137} \mathrm{Cs}$ & 661.6 & 0.02635 & 1.8 & 0.02517 & 0.96 & 0.024548 & 0.5 & 0.02422 & 0.99 \\
\hline${ }^{54} \mathrm{Mn}$ & 834.0 & 0.02186 & 0.7 & 0.02165 & 0.99 & 0.020651 & 0.0 & 0.02084 & 1.01 \\
\hline${ }^{88} \mathrm{Y}$ & 898.0 & 0.01832 & 1.1 & 0.01883 & 1.03 & 0.017901 & 0.5 & 0.01815 & 1.01 \\
\hline${ }^{65} \mathrm{Zn}$ & 1115.0 & 0.01721 & 1.5 & 0.01735 & 1.01 & 0.016356 & 0.4 & 0.01677 & 1.03 \\
\hline${ }^{60} \mathrm{Co}$ & 1173.0 & 0.01529 & 0.4 & 0.01532 & 1.00 & 0.014415 & 0.1 & 0.01486 & 1.03 \\
\hline${ }^{60} \mathrm{Co}$ & 1333.0 & 0.01359 & 0.4 & 0.01391 & 1.02 & 0.01299 & 0.0 & 0.01350 & 1.04 \\
\hline${ }^{88} \mathrm{Y}$ & 1836.0 & 0.01063 & 0.8 & 0.01121 & 1.05 & 0.010237 & 0.1 & 0.01094 & 1.07 \\
\hline
\end{tabular}

${ }^{(*)}$ Relative error of MCNP calculations are lower than $1 \%$.

Some 93 MCNP models have been developed using the 17 variables listed in Table 2. A value is chosen for each variable according to its PDF. The result of the calculation is composed by 93 MCNP outputs, each of them defined by a geometry with 17 different parameters. According to these values, the efficiency corresponding to each radionuclide is calculated. As a result, 93 efficiency curves are obtained.

To understand the effects on the efficiency of the inactive layer and other geometrical variables, an uncertainty analysis of some parameters of the HPGe crystal has been performed using the Noether-Wilks formula. Three inactive layers have been taken into account: top, lateral and inner hole. The rest of variables considered are listed in Table 2. They include different parameters of the detector (crystal, window and end-cap), the Petri dish as well as the distance Petri-detector. 

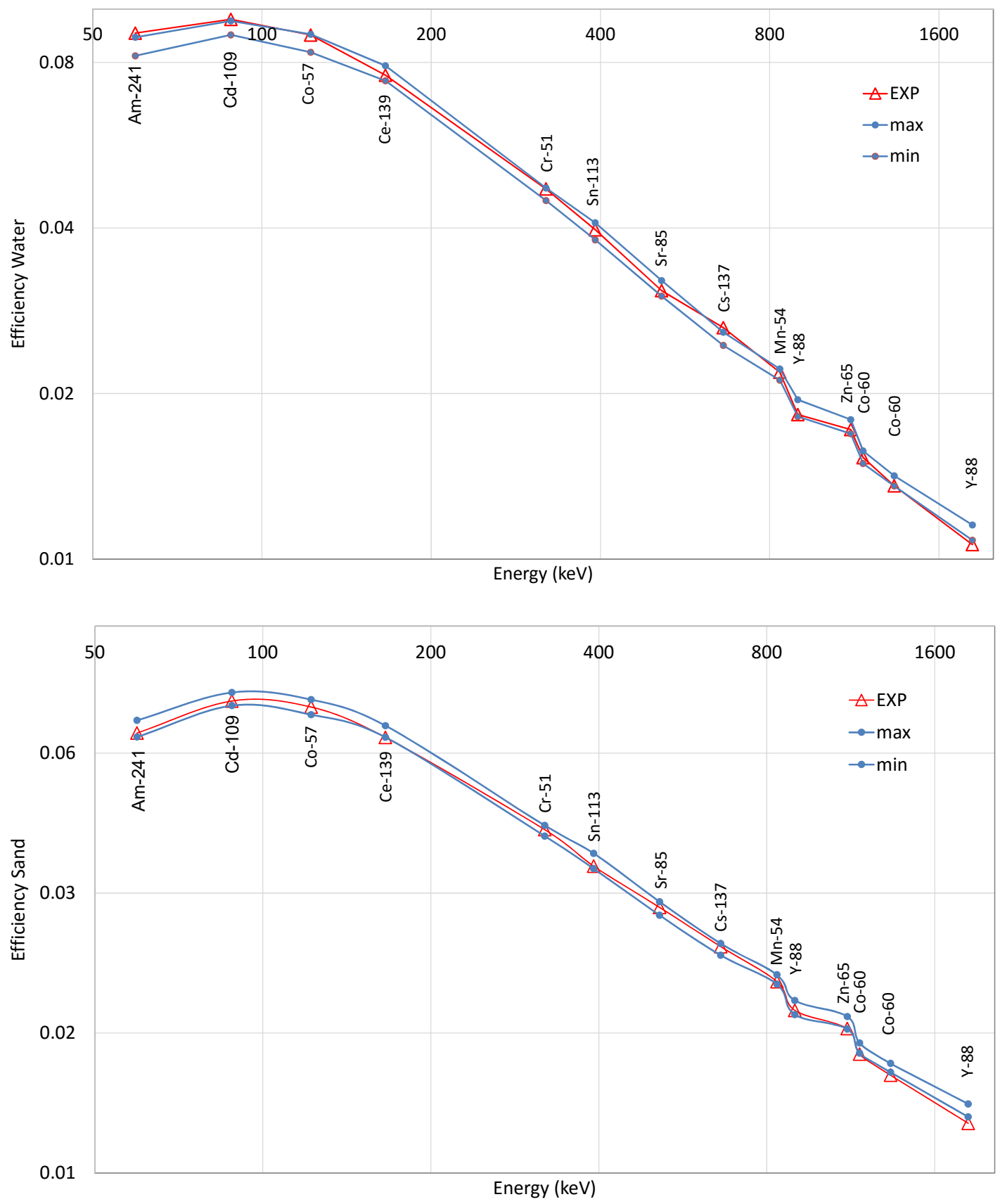

Figure 2. Wilks analysis Petri a) Water and b) Sand.

Applying the Wilks analysis, 93 MCNP5 outputs are obtained. The 93 efficiency values calculated for each radionuclide follow a normal distribution. To better represent those results of the 93 simulations, only the maximum and minimum are shown in Figure 2.

Results for Petri dish filled with both water and sand, show that not all of the experimental results are within the limits $\mathrm{L}$ and $\mathrm{U}$, minimum and maximum values respectively for the efficiency obtained from 93 simulations. According to Wilks conclusions, the interval [L, U] would cover $95 \%$ of the efficiency values for the $95 \%$ of the sets of simulations, but some radionuclides fail in that ${ }^{241} \mathrm{Am},{ }^{109} \mathrm{Cd},{ }^{137} \mathrm{Cs}$ and ${ }^{88} \mathrm{Y}$ do not accomplish that for Petri dish filled with water and ${ }^{60} \mathrm{Co}$ and ${ }^{88} \mathrm{Y}$ for Petri dish filled with sand. In these latter cases, the intervals obtained underestimate the efficiencies, with significative difference between experiments and simulations. 
In the high energy interval $\left({ }^{88} \mathrm{Y}\right.$ and $\left.{ }^{60} \mathrm{Co}\right)$, slight discrepancies can be attributed to the estimation of the true coincidence summing correction factor. ${ }^{88} \mathrm{Y}(1836 \mathrm{keV})$ is out of the coverage interval, $3 \%$ of relative difference respect to the lower limit for both water and sand cases.

Regarding to the low energy interval, the main discrepancies are observed for ${ }^{241} \mathrm{Am}(1.7 \%$ out of upper limit) and ${ }^{109} \mathrm{Cd}(0.7 \%$ out of upper limit). In this case, these discrepancies can be due to the estimated dead layer $(75 \mu \mathrm{m})$.

All of the intervals obtained result to be highly homogeneous, with coefficients of variation lower to $1.9 \%$, compared with the uncertainty of input parameters $(5 \%)$. That corroborates that the coverage/confidence intervals obtained through 93 simulations allow providing a good approximation to the real value of the experimental efficiency taking into account the uncertainty with respect to physical parameters of detector and source for most cases.

Results of the efficiency from those 93 MCNP simulations present a Normal distribution for each radionuclide, so they can be used to obtain more precise results.

\section{CONCLUSIONS}

The MCNP5 code has been applied to calculate the efficiency curve of the HPGe detector used in the LRA of UPV. Uncertainty analysis has been performed using the Noether-Wilks formula. The uncertainty analysis considers 17 variables, corresponding to geometrical parameters of the detector, the source and the distance source-detector. A normal PDF has been assigned to each variable, with a standard deviation of $5 \%$.

A satisfactory agreement is achieved in practically the entire energy range of interest. The most relevant discrepancy is observed for ${ }^{88} \mathrm{Y}(1836 \mathrm{keV})$, which is slightly out of the coverage interval $(3 \%)$. In the low energy range, ${ }^{241} \mathrm{Am}$ and ${ }^{109} \mathrm{Cd}$ are also out of the interval $(2 \%)$. All of the intervals obtained result to be highly homogeneous, with coefficients of variation lower than $1.9 \%$, compared with the uncertainty of input parameters $(5 \%)$.

\section{REFERENCES}

Agostinelli, S., et al., 2003. GEANT4- a simulation toolkit. Nucl. Instrum. Methods Phys. Res. A 506, 250-303.

Andreotti, E., Hult, M., Marissens, G., Lutter, G., Garfagnini, A., Hemmer, S., von Sturm, K., 2014. Determination of dead-layer variation in HPGe Detectors. App. Radiat. Isotopes 87, 331335.

Blank, B., Souin, J., Ascher, P., Audirac, L., Canchel, G., Gerbaux, M., Grévy, S., Giovinazzo, J., Guérin, H., Kurtukian Nieto, T., Matea, I., Bouzomita, H., Delahaye, P., Grinyer, G. F., Thomas, J. C, 2015. High-precision efficiency calibration of a high-purity co-axial germanium detector. Nucl. Instr. Meth. Phys. Res. A 776, 34-44.

Chham, E., Garcia, F. P., El Bardouni, T., Ferro-Garcia, M. A., Azahra, M., Benaalilou, K., Krikiz, M., Elyaakoubi, H., El Bakkali, J., Kaddour, M., 2015. Monte Carlo analysis of the influence of germanium dead layer thickness on the HPGe gamma detector experimental efficiency measured by use of extended sources App. Radiat. Isotopes 95, 30-35.

Conti, C.C., Salinas, I. C. P., Zylberberg, H., 2013. A detailed procedure to simulate an HPGe detector with MCNP5. Prog. Nucl. Energy 66, 35-40. 
Crow, E. L., Statistics manual with examples taken for ordenance development, New York Dover Publications, 1960.

Debertin, K., Helmer, R.G., Gamma and X-Ray Spectrometry with Semiconductor Detectors. North-Holland, Amsterdam, 1988.

Eren Belgin, E., Aycik, G. A., 2015. Derivation of an efficiency-calibration simulation for a welltype HPGe detector using the Monte Carlo approach and analytical techniques. Radiat. Meas. 73, $36-45$.

Galeser, H., Hofer, E., Kloos, M., Skorek, T., 1994. Uncertainty and sensitivity analysis of a postexperiment calculation in thermal-hydraulics. Reliab. Eng. Syst. Safe. 45, 19-33.

Guba, A., Makai, M., Pál, L., 2003. Statistical aspects of best estimate method-1. Reliab Eng. Syst. Safe. 80, 217-232.

JCGM 101:2008, Evaluation of measurement data - Suplement 1 to the "Guide to the expression of uncertainty in measurement" - Propagation of distributions using a Monte Carlo method, JCGM 2008.

Lepy, M. C., Ferreux, L., Pierre, S., 2012. Coincidence summing corrections applied to volumen sources. App. Radiat. Isotopes 70, 2137-2140.

Montgomery D. M., and Montgomery G, A., 1995. A method for assessing and correcting coincidence summing effects for germanium detector efficiency calibrations, Journal of Radioanalytical and Nuclear Chemistry Articles, 93, 71-79.

Ngo Q. H., 2010. The influence of dead layer thickness increase on efficiency decrease for a coaxial HPGe p-type detector. Nucl. Instr. Meth. Phys. Res. A 621, 390-394.

Nikolic, J., Vidmar, T., Jokovic, D., Rajacic, M., Todorovic, D., 2014. Calculation of HPGe efficiency for environmental samples: comparison of EFFTRAN and GEANT4. Nucl. Instr. Meth. Phys. Res. A 763, 347-353.

Ródenas, J., Gallardo, S., Ballester, S., Primault, V., Ortiz, J., 2007. Application of the Monte Carlo method to the analysis of measurement geometries for the calibration of a HP Ge detector in an environmental radioactivity laboratory. Nucl. Instr. Meth. Phys. Res. B 263, 144-148.

Salvat, F., Fernández-Varea, J. M., Sempau, J. PENELOPE, a code system for Monte Carlo simulation of electron and photon transport, Issy-les-Moulineaux: OECD/NEA Data Bank, 2011.

Vidmar, T., Capogni, M., Hult, M., Hurtado, S., Kastlander, J., Lutter, G., Lepy, M. C., Martinkovic, J., Rameback, H., Sima, O., Tzika, F., Vidmar, G., 2014. Equivalence of computer codes for calculation of coincidence summing correction factors. App. Radiat. Isotopes 87, 336341.

Wilks, S. S., Mathematical statistics, John Wiley \& Sons, 1962.

X-5 MONTE CARLO TEAM, "MCNP - A General Monte Carlo N particle Transport Code, Version 5" LA-UR-03-1987, Los Alamos National Laboratory, April, 2003. 